\title{
CONSTRUÇÃO COLETIVA DE UMA TRILHA ECOLÓGICA NO CERRADO: PESQUISA PARTICIPATIVA EM EDUCAÇÃO AMBIENTAL
}

\section{Collective construction of an ecological track in cerrado: participative research in environmental education}

\author{
Juliana Lacorte Cazoto ${ }^{1}$ \\ Marília Freitas de Campos Tozoni-Reis ${ }^{2}$
}

\begin{abstract}
Resumo: Dentre os muitos temas ambientais que podem ser problematizados pela Educação Ambiental encontra-se a proteção aos ecossistemas. Definiu-se como tema, num projeto de Educação Ambiental, o Cerrado, bioma amplamente degradado por ações antrópicas e que faz parte do ambiente natural de Botucatu, interior de São Paulo. Com o objetivo de despertar um olhar crítico-ambiental, visando a integração do ambiente natural e urbano, o projeto, realizado com alunos da $8^{a}$ série do Ensino Fundamental, teve como eixo a construção de uma Trilha Ecológica no Cerrado. Todo o processo de planejamento, realização e avaliação da trilha foi participativo: os participantes estudaram as características do Cerrado; identificaram, na área, as espécies remanescentes; discutiram as condições de conservação da área, e tomaram decisões sobre a construção da trilha como recurso educativo. Problematizaram, coletivamente, a interação comunidade-ambiente, articulando consciência ambiental e ação educativa, concluindo sobre o potencial desencadeador deste recurso para reflexões sobre temas socioambientais. O grupo teve a oportunidade de vivenciar um trabalho educativo com crianças da educação infantil, concretizando a trilha como recurso didático-pedagógico na aproximação "visitantes-educandos-ambiente".
\end{abstract}

Palavras-chave: Pesquisa-participativa. Educação ambiental. Trilha ecológica. Cerrado.

\begin{abstract}
Among many subjects that could be debated by environmental education, we could mention the preservation of natural resources. We define the Cerrado, which is a biome largely degraded by human actions and part of the natural environment of Botucatu - SP, as theme for an environmental education project. With the intention of creating special ecological attention that aims at the integration of natural and urban environments, this project, that was done with students from the 8 grade of Fundamental School, was concerned with the creation of an Ecological Track in the Cerrado. All the processes of planning, realization and analysis of the track were participative: the students investigated the Cerrado features, identified main species of the biome, discussed the conservation conditions of the area and took decisions about the track's construction as an educative resource. During this process, they questioned themselves about the interaction between community and the environment, joining environmental knowledge and educative action, concluding that this is an important instrument in reflections about the social and ecological themes. The group had the opportunity of using the track with early childhood education children, characterizing it as a didactic-pedagogic resource within the "visitors-environment approach".
\end{abstract}

Key words: Participative research. Environmental education. Ecological track. Cerrado.

${ }^{1}$ Graduada em Ciências Biológicas (Licenciatura).<cazoto@unicamp.br>

${ }^{2}$ Pedagoga. Docente, Departamento de Educação, Instituto de Biociência de Botucatu, Universidade Estadual Paulista (Unesp). Botucatu, SP. <mariliaedu@ibb.unesp.br>

${ }^{1}$ Rua José Carlos Pavanelli, 129

Jaú, SP

$17.211-550$ 


\section{Introdução}

O modelo de civilização construído pela sociedade moderna tem consolidado a tendência ao desequilíbrio ambiental. Esse modelo interfere no desperdício de energia e desestabilização das condições de equilíbrio por razões de ordem biológica, social, política, cultural e econômica. Assim, para satisfazer suas necessidades, o homem impõe uma pressão cada vez maior sobre esse ambiente. Durante anos, a sociedade conviveu com as conseqüências da degradação ambiental, com o argumento de que esses prejuízos eram necessários à produção, uma vez que a concepção de progresso e desenvolvimento sempre esteve associada à degradação do meio, ao domínio da natureza e ao homem como um ser superior, resultando, na sociedade moderna, em ações profundamente predatórias, ações antiecológicas (CASTRO, 1999). Desde a década de 1970, essa lógica de desenvolvimento tem sido discutida pelos ambientalistas e por setores da sociedade mais comprometidos com uma organização social mais justa e equilibrada, tanto do ponto de vista social quanto do ponto de vista ambiental, no sentido de propor e realizar ações que enfrentem os problemas que se avolumam.

Partindo do pressuposto de que a conservação do meio, relacionada com a qualidade de vida da sociedade, é responsabilidade de todos, a Educação Ambiental (EA), discutida em diferentes espaços educativos, assume, cada vez mais, uma função crítica e transformadora, cujos objetivos dizem respeito à co-responsabilização dos indivíduos na promoção de um novo tipo de desenvolvimento, um novo modelo civilizatório com perspectiva sustentável (LEFF, 2001). Nessa linha, muito se tem discutido sobre a EA como condição necessária para se enfrentar o quadro de crescente degradação socioambiental, como estratégia para a sustentabilidade.

A EA apresenta, segundo Ab'Saber (1994), a tarefa de promover um processo de conscientização, por meio do processo educativo, que envolva ciência e ética, e uma renovada filosofia de vida, proporcionando, às pessoas, instrumentos para construírem sua História e recuperarem características essenciais da condição humana, para, sobretudo, refletirem sobre o futuro do planeta. Entretanto, embora muitos esforços significativos tenham marcado o fecundo caminho trilhado pela EA, é preciso transformá-la, segundo Jacobi (2003), em mais uma ferramenta de mediação necessária entre culturas, comportamentos diferenciados e interesses de grupos sociais para a construção das transformações desejadas.

Ainda nesta linha, pensemos que, para que o ambiente mantenha-se num grau de conservação aceitável, é importante definir algumas áreas naturais conservadas e garantir a recomposição de outras. Santos et al. (2000) discutem os aspectos essenciais dessa tarefa educacional, que tem, como ponto de partida, o processo de conscientização, seguindo até a ação propriamente dita. Ele estabelece relação entre a consciência da problemática ambiental, a busca pelo conhecimento do tema em questão, o envolvimento com a temática, a criação de um senso de responsabilidade, que gera a ação que resulta na conscientização de um número cada vez maior de pessoas, para que um processo seja desencadeado. Assim, a tarefa da EA, ao tomar um tema como ponto de partida para o processo educativo, é promover sensibilização, conhecimento e ação numa perspectiva coletiva. Assim, compreendemos a EA como transformadora, no sentido dado por Loureiro (2004, p. 29):

Educação que procura entender a realidade objetiva sem considerar os sujeitos e a subjetividade é objetivismo e negação da ação históri- 
Construção coletiva de um trilha ecológica...

ca (assim, o máximo que podemos fazer é interpretar o mundo e não o transformar). Educação que é exclusivamente voltada para o "eu" isolado da sociedade, para a subjetividade sem objetividade, é psicologismo, subjetivismo, negação da realidade para além da consciência e da ação consciente dos sujeitos na sua constituição.

Pautados na idéia de que o processo educativo ambiental é amplo, complexo e histórico, compreendemos também que ele pode acontecer em diversos grupos da sociedade: discussões podem ser incentivadas em grupos industriais ou sindicalistas, com idosos, adultos, jovens ou crianças. O incentivo a questionamentos e a apropriação do conhecimento por várias pessoas, sujeitos desse processo de conscientização, são importantes formas de contribuir para a articulação social e a formação de cidadãos conscientes e ativos no cuidado ambiental, dedicados ao ambiente da comunidade. Neste sentido, os projetos educativos temáticos são parte de um processo educativo ambiental mais amplo, de conscientização ambiental.

Dentre os variados temas ambientais que preocupam o movimento ambientalista e a EA, está a proteção dos ecossistemas. Apesar de o Brasil ter avançado nas medidas de proteção do ambiente natural, as suas dimensões continentais, a diversidade de biomas presentes no território nacional, e, sobretudo, o modelo de desenvolvimento adotado, indicam que as condições de conservação em que se encontram os ecossistemas exigem ações urgentes de conservação. Dentre essas, estão as ações educativas ambientais.

O cerrado é um bioma que se encontra numa situação preocupante do ponto de vista da degradação: é um tipo peculiar de vegetação que está presente na maior parte dos estados brasileiros e, ao mesmo tempo, apresenta maior impacto no que diz respeito à destruição. Segundo Coutinho (2002), podemos observar grande diversidade de fauna e flora em áreas relativamente pequenas de cerrado, pois a maioria da sua área é ocupada por pastagens e plantações. A região de Botucatu, interior de São Paulo, além de apresentar fragmentos de cerrado, é também zona de recarga do Aqüífero Guarani, um dos maiores reservatórios de água subterrânea do mundo, que está circundada pela zona urbana e rural, nas fazendas de gado. Dessa forma, para garantir o reabastecimento do aqüifero, é indispensável a conservação do ambiente natural da região.

Com o objetivo de contribuir para o desenvolvimento da consciência ambiental de uma parcela da população que vive no entorno de uma área-fragmento de cerrado, contribuindo, também, para despertar um olhar crítico no meio em que vivemos, desenvolvemos um projeto de EA para a construção de uma trilha cológica na área onde se encontram fragmentos de cerrado num bairro da cidade de Botucatu. Uma trilha ecológica, por ser um interessante recurso didático-pedagógico, contribui para desencadear discussões e reflexões indispensáveis à aproximação dos educandos com o ambiente natural, estratégia importante para se conhecer e cuidar do ambiente em que vivemos, neste caso, o cerrado.

\section{Metodologia}

Durante muito tempo, a humanidade vem procurando maneiras para conhecer e compreender a vida. A produção de conhecimentos, que caracteriza os processos de pesqui- 
sa, tem como fundamentos metodologias que, historicamente, se abrigam sob paradigmas da ciência moderna, clássica e tradicional. No entanto, outras metodologias vêm se desenvolvendo, abrigadas em novos paradigmas científicos e sociais.

A pesquisa-ação, enquanto modalidade de pesquisa associada a diversas formas de ação coletiva, é orientada em função da resolução de problemas ou de objetivos de transformação (THIOLLENT, 2000), e tem como meta a interação pesquisador-sociedade. Ela tem compromisso com a prática educativa, valorizando a participação das pessoas que estão inseridas no projeto de pesquisa, não só como "objetos" de estudo ou como fonte de dados, mas mobilizando-as a pôr em prática os conceitos e assuntos discutidos em grupo: a pesquisa-ação é inteiramente direcionada para a intrínseca ligação teoria e prática (DEMO, 1989). Por outro lado, sabemos que os métodos tradicionais de pesquisa, apesar de contribuírem para a produção de conhecimentos, tendem a excluir as pessoas envolvidas no processo de aprendizagem: os educandos. Se estes puderem se expressar, colaborar com a produção de idéias e informações, e construir conhecimentos e ações em parceria com os pesquisadores, o processo de produção de conhecimentos, assim como o processo de conscientização que dele emerge, poderá ser mais rico e produtivo. Quando este conjunto de conhecimentos e ações por parte das pessoas ou grupos implicados no problema em questão se consolida, pode-se, então, se qualificar a pesquisa e pesquisa-ação (THIOLLENT, 2000).

Atualmente, muito valorizada na EA, a pesquisa-ação-participativa, segundo TozoniReis e Tozoni-Reis (2004), está vinculada a uma ação conscientemente política, no sentido de aliar produção de conhecimento e mudança social. Entendendo a apropriação e construção crítica de conhecimentos e a ação como parcelas indissociáveis do processo educativo ambiental, vemos a pesquisa-ação-participativa como adequada para o desenvolvimento deste estudo.

Com essas orientações, como recurso para sensibilizar a população do entorno de uma área-fragmento de cerrado para garantir os conhecimentos e compreensão necessários aos cuidados com esse ambiente natural, foi empreendida a construção da trilha ecológica, por um grupo de quatro pesquisadores-estudantes da $8^{a}$ série do Ensino Fundamental da escola Sophia Gabriel, situada no bairro da Cohab em Botucatu-SP. Nossos estudos e ações ambientais foram realizados em 29 reuniões, que aconteceram na escola durante todo o ano de 2005.

\section{Desenvolvimento}

O estudo teve, como principal objetivo, promover a participação de estudantesmoradoras do entorno da área-fragmento de cerrado na construção de uma trilha ecológica adequada às características desta população, promovendo, ao mesmo tempo, um processo educativo ambiental. $\mathrm{O}$ tema cerrado foi tomado como tema gerador de discussão, reflexão e análises, resultando em atividades que aconteceram no ambiente escolar, e, em grande parte do estudo, no contato direto dos participantes com o ambiente natural.

Para alcançar outro objetivo do estudo, a formação de um grupo de pesquisa com o interesse em comum pelo cerrado e pelo ambiente como um todo, convidamos os alunos da $8^{a}$ série do Ensino Fundamental da escola Sophia Gabriel, em Botucatu-SP. O próximo passo foi estabelecer, com os estudantes, a importância de cada um dentro do grupo e da pesquisa. O processo de formação do grupo se mostrou complexo e dinâmico, promovendo a saída 
de alguns participantes logo nas primeiras reuniões, e a entrada de outros participantes posteriormente, tornando-se, curiosamente, um grupo feminino. A percepção da importância de cada uma delas nas atividades do grupo chamou a atenção de todas, e deixou explícitos os princípios da autonomia, continuidade, participação e cooperação, que a ação educativa ambiental exige no decorrer de suas atividades, demonstrando que elas, estudantes da $8^{a}$ série do Ensino Fundamental, eram indispensáveis para o bom andamento da pesquisa, e não eram apenas "objetos de estudo" - superando o que discute Demo (1989) como "violência contra a realidade social", destacando a não restituição do conhecimento construído e adquirido por meio dos trabalhos desenvolvidos com a colaboração das comunidades, além de colocar tal conhecimento a serviço do sistema dominante, que o usa para refinar as estratégias de controle social.

É importante destacar que a relação do grupo se manteve em evolução durante todo o desenvolvimento do trabalho, e, utilizando-se das oportunidades que a pesquisa ação-participativa proporciona, evoluiu de um plano superficial para o relacionamento interpessoal mais profundo. Definidas as relações interpessoais primordiais para o desenvolvimento da pesquisa, o tema cerrado entrou em questão, e as atividades coletivas, para o início do projeto, se iniciaram. Antes da construção da trilha, entretanto, um objetivo importante tinha de ser alcançado: o reconhecimento e entendimento do bioma. As saídas ao campo para observação, que fizeram parte da maioria das reuniões, despertaram o interesse do grupo pelas peculiaridades de cada planta, ainda que quase a totalidade apresentasse as características morfológicas típicas do cerrado. Vivenciou-se, por essa experiência de campo, a articulação entre o ensino e a pesquisa: as aulas práticas, in loco, estimularam a percepção do ambiente pelas estudantes participantes do grupo. Segundo Mello (2003), a "aula passeio", técnica da pedagogia Freinet, permite a ampliação das fontes de informação dos temas estudados na sala de aula, propiciando e ensinando uma atitude investigativa para os participantes. Ainda que, nas reuniões que ocorreram no decorrer do Projeto, as características tradicionais do ensino tenham sido evitadas, as saídas a campo ofereceram a oportunidade de desenvolvimento da capacidade investigativa dos participantes. A curiosidade, expressa pela atenção de todas e pelas perguntas freqüentes, ampliou o interesse pelo tema do Projeto, e também proporcionou a discussão de assuntos que não seriam discutidos ou percebidos sem as saídas do grupo. As visitas à área estudada desencadearam as primeiras análises e a descoberta das características morfológicas marcantes da vegetação: as árvores tortuosas e com cascas grossas; folhas ásperas com anexos como pêlos, espinhos e cera; o solo seco. As meninas propuseram a identificação de algumas espécies mais comuns e características do cerrado na literatura especializada. Estudo realizado, pelo grupo, sobre a vegetação do cerrado foi importante para desencadear discussões sobre a relação homem-ambiente e ambiente natural-ambiente urbano. Essa abordagem também incentivou a idéia de construir um mapa de vegetação do bairro, indicando locais onde havia vegetação nativa, vegetação exótica ao cerrado e pastagem.

Os temas do desmatamento e poluição estiveram presentes no decorrer das discussões, sobretudo quando estávamos no campo. O entendimento do cerrado como bioma que sofre com a capacidade humana de modificar o ambiente, na lógica da sociedade capitalista, estimulou o grupo a discutir fatores políticos, sociais, econômicos e ecológicos do tema. É importante ressaltar que, nas discussões, observamos a influência da televisão no aprendizado dos jovens estudantes. Várias vezes durante o desenvolvimento do projeto, temas veiculados pela televisão foram comentados no grupo. Segundo Almeida, Nascimento e Quaioti (2002), 
a televisão tem papel importante na sociedade atual, representando grande fonte de informação sobre o mundo. Desta forma, é importante que os processos educativos tragam os temas veiculados para a apreciação crítica: nem negando nem aderindo passivamente às idéias.

A busca da relação entre a teoria e a prática se fez presente no trabalho, realizando, dessa maneira, seu principal objetivo: a construção da trilha. A escolha dos caminhos a serem percorridos levantou discussões que priorizaram lugares que caracterizassem o cerrado, as condições de poluição e desmatamento do mesmo, sem descuidar da acessibilidade, importante para conseguirmos atingir diversos tipos de visitantes-educandos. Por último, a decisão final, exaustivamente discutida, foi a de que a nossa trilha deveria ser feita sem abrir caminho pelo cerrado, apenas utilizando os caminhos já existentes. As discussões, 'troca de idéias' no grupo, fazem parte do desenvolvimento da pesquisa-ação, por concretizarem a participação dos diferentes sujeitos envolvidos, um dos pressupostos mais importantes desta metodologia (JANKE, TOZONI-REIS, 2005).

$\mathrm{Na}$ etapa de construção da trilha, foram confeccionadas oito placas de identificação com os nomes científico e popular das espécies de cerrado. Elas foram colocadas no trajeto traçado: Anadenanthera falcata, Stryphnodendron obovatum, Miconia albicans, Schfflera vinosa, Solanum bycocarpum, Styrax ferrugineus, Baubinia rufa, Rapanea umbellata. Problemas surgiram na colocação das placas: algumas foram roubadas do local, sendo jogadas no meio da vegetação sem as correntes e parafusos. Essas atitudes reiteram as condições sob as quais vivemos, e mostram que a educação - inclusive a ambiental - nos mostra caminhos e alternativas para a mudança do meio em que vivemos, sendo uma das principais saídas para a mudança de atitude dos indivíduos em sociedade. O fato desencadeou discussões acerca dos motivos e implicações que levaram pessoas a terem esse comportamento.

Após organizar o material construído pelo grupo, partimos para o último objetivo: a apresentação da trilha. Tal atividade havia sido planejada para os próprios alunos da escola Sophia Gabriel, estudantes de outras séries, entretanto, alguns problemas decorrentes da organização da vida escolar impossibilitaram essa visita. A visita monitorada por nós à trilha era importante, pois em nossa proposta de pesquisa ação-participativa colocamos, como princípio, a ação do grupo na comunidade. Segundo Vasconcelos (1997), a pesquisa ação-participativa deve procurar integrar as alternativas de análise e de solução dentro do processo investigativo para a mudança de estruturas sociais. Dentre as diversas alternativas para a visita, uma se fez mais acertada: um grupo de crianças da educação infantil que estava estudando o tema cerrado. Durante a visita, alguns pontos foram especialmente trabalhados: as características da vegetação, a diversidade de espécies, os cuidados com o lixo e a caracterização de áreas degradadas.

Foi interessante observar que o grupo de estudantes-pesquisadoras viveu um processo de amadurecimento no decorrer do ano, superando alguns problemas de convivência e afinidade, comuns na convivência grupal. Além disso, pudemos observar que as atitudes mais diretas e cotidianas em relação ao ambiente foram desenvolvidas. Um ponto discutido em EA, e em pesquisa ação-participativa, é a capacidade de "conhecer" e "transformar" (agir). Pensando nessa perspectiva, pudemos entender a evolução da capacidade de discussão consciente sobre os aspectos socioambientais do cerrado, vivenciando um processo de apropriação e construção crítica de conhecimentos.

Um dos objetivos do processo que vivenciamos foi a percepção da importância de cada indivíduo na sociedade e no ambiente em que ele vive. Sob este aspecto, a convivência 
Construção coletiva de um trilha ecológica...

dentro do grupo, durante o ano, proporcionou a certeza de que esta percepção diferenciada do mundo esteve presente, ainda que sutilmente, entre nossos participantes. Segundo Winn e Porcher (1975), a relação do grupo proporciona benefícios, como: desenvolvimento intelectual, de confiança, controle de emoções, diminuição do egocentrismo, mudança de comportamento. O desenvolvimento intelectual (capacidade crítica) e a mudança de comportamento foram as características mais marcantes que se aprimoraram durante o projeto. Da formação do grupo até a apresentação da trilha, as meninas adquiriram a capacidade de se comunicar com as pessoas, transmitindo o conhecimento construído durante todo esse processo.

\section{Considerações finais}

A EA promove conscientização, um processo que se dá na relação entre o "eu" e o "outro", pela prática social reflexiva e fundamentada teoricamente. A ação conscientizadora é mútua, envolve: capacidade crítica, diálogo, a assimilação de diferentes saberes, e a transformação ativa da realidade e das condições de vida (LOUREIRO, 2004). Dessa maneira, entendemos o processo educativo apresentado neste artigo como "apropriação/transmissão crítica e transformadora da totalidade histórica e concreta da vida dos homens no ambiente" (TOZONI-REIS, 2003). O trabalho buscou, a cada objetivo alcançado, traçar e concretizar essa apropriação e transmissão crítica, proporcionando a compreensão das possibilidades que podemos ter com grupos participativos na construção de atitudes e conhecimentos.

A construção da trilha do cerrado, tomada como "tema gerador" de um processo educativo ambiental mais amplo, garantiu avanço nas discussões e nas decisões dos participantes, indicando que a metodologia da pesquisa-ação-participativa, apesar das dificuldades que tivemos no processo de formação do grupo, foi adequada aos objetivos do Projeto, criando, também, possibilidades de continuidade das ações educativas.

Todos os objetivos do estudo voltaram-se para um processo de EA undamentado na metodologia da pesquisa ação-participativa, em parceria com estudantes. Esses objetivos foram alcançados, uma vez que os conhecimentos foram construídos, discutidos, planejados e colocados em prática, estabelecendo-se, com êxito, um processo de EA. No entanto, consideramos essa tarefa incompleta, pois todo processo educativo, em especial o ambiental, exige continuidade. A metodologia da pesquisa-ação reúne as condições necessárias para se atingir esse objetivo: garantir o entendimento do ambiente em que vivemos, interpretá-lo e reunir idéias e ações que se desenvolvam e modifiquem esse ambiente, atingindo outras tantas pessoas que também se encontram nele, criando, portanto, condições de autonomia e continuidade.

\section{Referências}

AB'SABER, A. N. (Re)conceituando educação ambiental. In: MAGALHÃES, L. E. (Org.). A questão ambiental. São Paulo: Terra Graph, 1994. p. 1-4.

ALMEIDA, S. S.; NASCIMENTO, P. C. B. D.; QUAIOTI, T. C. B. Quantidade e qualidade de produtos alimentícios anunciados na televisão brasileira. Rev. Saúde Pública , v. 36, n. 3, p. 353-5, 2002. 
CASTRO, E. M. N. V. Diálogo com a vida: uma educação consciente. In: FILHO, L. E. M. et al. (Orgs.). Meio ambiente \& educação. Rio de Janeiro: Gryphus, 1999. p. 9-19.

COUTINHO, L. M. O bioma do cerrado. In: KLEIN, A. L. (Org.). Eugen Warming e o cerrado brasileiro. São Paulo: Editora Unesp, 2002. p. 77-92.

DEMO, P. Metodologias alternativas: algumas pistas introdutórias. In:

Metodologia científica em ciências sociais. 2. ed. São Paulo: Atlas, 1989. p. 229-57.

JACOBI, P. Educação ambiental, cidadania e sustentabilidade. Cadernos de Pesquisa, São Paulo, n. 118, p. 89-205, 2003.

JANKE, N.; TOZONI-REIS, M. F. C. Qualidade de vida e educação ambiental: construção coletiva de significados pela pesquisa-ação-participativa. In: REUNIÃO ANUAL DA ANPED, 28., 2005, Caxambu. Anais... Caxambu, 2005. 1 CD-ROM.

LEFF, E. Saber ambiental: sustentabilidade, racionalidade, complexidade, poder. Petrópolis: Vozes, 2001.

LOUREIRO, C. F. B. Trajetória e fundamentos da educação ambiental. São Paulo: Cortez, 2004.

MELLO, S. A. Aula passeio. Botucatu, 2003. (Apostila).

SANTOS, J. E. et al. Environmental education praxis toward a natural conservation area. Revista Brasileira de Biologia, São Carlos, v. 60, n. 3, p. 361-72, 2000.

THIOLLENT, M. Metodologia da pesquisa-ação. São Paulo: Cortez, 2000.

TOZONI-REIS, M. F. C. Pesquisa em educação ambiental na universidade: produção de conhecimentos e ação educativa. In: TALAMONI, J. L. B.; SAMPAIO, A. C. (Orgs.). Educação ambiental: da prática ambiental à cidadania. São Paulo: Escrituras, 2003. p. 9-21.

.; TOZONI-REIS, J. R. Conhecer, transformar e educar: fundamentos psicossociais para a pesquisa-ação-participativa em educação ambiental. In: REUNIÃO ANUAL DA ANPED, 27., 2004, Caxambu. Anais... Caxambu, 2004. 1 CD-ROM.

VASCONCELOS, H. S. R. A pesquisa-ação em projetos de educação ambiental. In: PEDRINI, S. G. (Org). Educação ambiental: reflexões e práticas contemporâneas. 3. ed. Petrópolis: Vozes, 1997.

WINN, M.; PORCHER, M. A. Como educar crianças em grupo: técnicas para entreter as crianças. 1. ed. São Paulo: IBRASA, 1975.

Artigo recebido em maio de 2008 e aprovado em novembro de 2008. 